\title{
Dapsone is a Potent Cause for Iatrogenic Methemoglobinemia: A Case Report
}

\author{
Faria Mumtaz ${ }^{1}$, Ayesha Niazi ${ }^{2}$, Kashif Bangash ${ }^{3}$, Hassan Mumtaz ${ }^{4}$ and Shahzaib Ahmad ${ }^{5 *}$ \\ ${ }^{1}$ Postgraduate Medicine NESCOM, Pakistan \\ ${ }^{2}$ Consultant Physician Nescom Hospital, Pakistan \\ ${ }^{3}$ Consultant Urologist KRL Hospital, Pakistan \\ ${ }^{4}$ House Surgeon KRL Hospital, Pakistan
}

${ }^{5}$ King Edward Medical University Lahore, Pakistan

*Corresponding author: Shahzaib Ahmad, King Edward Medical University Lahore, Pakistan

\section{ARTICLE INFO}

Received: 㗀 December 16, 2020

Published: 㗀 January 05, 2021

Citation: Faria M, Ayesha N, Kashif B, Hassan M, Shahzaib A. Dapsone is a Potent Cause for Iatrogenic Methemoglobinemia: A Case Report. Biomed J Sci \& Tech Res 32(5)-2021. BJSTR. MS.ID.005326.

\section{ABSTRACT}

Methemoglobinemia is a blood disorder in which blood methemoglobin levels are $>1 \%$ leading to defective $\mathrm{O}_{2}$ supply to body tissues. It leads to a shift of the oxygen dissociation curve to the left. We present a case involving a young boy who was taking dapsone for 3 months, developed dyspnea and peripheral cyanosis, was diagnosed as methemoglobinemia, and was given antidote therapy. Patients with respiratory symptoms and cyanosis but normal $\mathrm{pO}_{2}$ in arterial blood gases and saturation gap $>5 \%$ have a high index of suspicion for methemoglobinemia.

Keywords: Methemoglobinemia; Dapsone; Methylene Blue; Saturation Gap

\section{Introduction}

Dapsone was synthesized about 100 years ago, but its use remained limited to leprosy and malaria due to its toxic effects. Recently, since the advent of HIV, it is widely used to treat Toxoplasma gondii encephalitis and Pneumocystis carinii pneumonia in acquired immune deficiency syndrome (AIDS). Its dermatological uses include treatment against dermatitis herpetiformis and linear immunoglobulin A (IgA) [1]. However, important but rare adverse effects of Dapsone include doserelated hemolysis and methemoglobinemia. Other side effects are psychosis, hypersensitivity syndrome, agranulocytosis, aplastic anemia, peripheral neuropathy, sulfone syndrome. Cyanosis in a patient with the use of dapsone has a high index of suspicion for the diagnosis of methemoglobinemia if saturation gap > 5\% [2] as in the case of our patient who was diagnosed and treated with IV methylene blue in time.

\section{Case Report}

A 17-year-old male presented to the emergency department with gradually progressive shortness of breath and bluish discoloration of lips, hands, nails and feet. No history of fever, cough, or hemoptysis. History revealed that he was diagnosed with Behcet's disease and was using dapsone $100 \mathrm{mg}$ per day and steroids for 3 months.General physical examination was normal except for peripheral cyanosis. He was vitally stable, but saturation was $77 \%$ at room air with bilateral equal air entry and no added sounds on auscultation of the chest. Saturation did not improve despite $\mathrm{O}_{2}$ inhalation. His baseline investigation showed TLC 12450, Hb 11.7, Platelets 253000, D Dimers<12, ABGs showed $\mathrm{pH}$ 7.432, $\mathrm{pO}_{2} 88, \mathrm{pCO}_{2} 27.7, \mathrm{HCO}_{3}$ 18.5, SATs $\mathrm{O}_{2}$ 97.2\%, CRP 0.3, $\mathrm{Hb}$ Electrophoresis showed no abnormality, G6PD 8.4 (5.5-20.5) ECG and chest X-ray was normal. HRCT chest done, which showed normal lung fields.Echocardiography was normal, with a $60 \%$ ejection fraction. Methemoglobin levels were 34\%. He was hence, diagnosed as Dapsone induced Methemoglobinemia and given methylene blue $1.5 \mathrm{mg} / \mathrm{kg}(100 \mathrm{mg})$ IV stat dose, then repeated daily for 2 more days till methemoglobin levels fell less than $10 \%$. Dapsone was discontinued. 


\section{Discussion}

Methemoglobin is different from hemoglobin as one or more of its four iron atoms are in ferric $\left(\mathrm{Fe}^{3+}\right)$ rather than ferrous $\left(\mathrm{Fe}^{2+}\right)$ state and incapable of binding oxygen [3]. Methemoglobinemia is a blood disorder where the MetHb level is $>1 \%$ of the $\mathrm{Hb}$ level in the blood, thus unable to release oxygen effectively to body tissues leading to the hypoxic condition [4]. Methemoglobin is naturally formed in the body at a rate of $3 \%$ per day in response to oxidative stress but is neutralized by 2 pathways to convert methemoglobin to hemoglobin, which is cytochrome b5-MetHb reductase pathway using NAD and nicotinamide adenine dinucleotide phosphate (NADPH)-MetHb reductase, using NADPH [5].

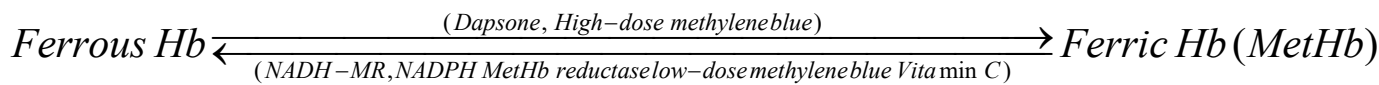

Methemoglobinemia can be hereditary or acquired. Hereditary forms are caused by deficiencies of cytochrome b5 reductase, or the presence of abnormal hemoglobin, hemoglobin $\mathrm{M}$ which is not capable of being reduced. Rarely it is caused by NADPHMetHb reductase and G6PD deficiency [4]. Causes of acquired methemoglobinemia described in the literature include exposure to oxidizing agents like nitrites (used as a food preservative), amyl nitrate (used as a recreational agent), abuse of paint thinner, intake of nitrate-containing vegetables, use of EMLA cream and Dapsone intake [6,7]. Modes of exposure can be ingestion, inhalation or absorption across the skin or mucous membranes. Nitrates have a direct oxidant effect on hemoglobin, while dapsone owes its oxidant potential to a metabolic product.

Some people are asymptomatic till 10\%-20\% of MetHb, but cyanosis may occur when MetHb reaches 15\%. When MetHb levels are in the range of $20 \%-45 \%$, the person may develop shortness of breath, cough, headache, lethargy, tachycardia, weakness, dizziness and tissue hypoxia, and when the level exceeds $45 \%$, the person may develop dyspnea, acidosis, cardiac dysrhythmias, heart failure, seizures, and coma. Severe methemoglobinemia may lead to death if not treated immediately [8]. In the presence of a high index of suspicion, Methemoglobinemia can be diagnosed via a "saturation gap" between the saturation recorded from the pulse oximeter as compared to the reported saturation in the arterial blood gas in setups with limited resources.

The antidote of choice for reversing methemoglobinemia is Methylene blue, an oxidizing agent. It should be used when MetHb is more than $30 \%$. Methylene blue is used in the dose of $1-2 \mathrm{mg} / \mathrm{kg}$ body weight intravenously every $5 \mathrm{~min}$. The dose can be repeated after $30 \mathrm{~min}$ if cyanosis does not improve. Since the source of NADPH is aerobic glycolysis in the red blood cells, methylene blue treatment should be accompanied by intravenous (IV) dextrose infusion. Methylene blue activates NADPH-MR in red blood cells to form leukomethylene blue, which acts as a reducing agent and convert the ferric ion $\left(\mathrm{Fe}^{3+}\right)$ back to its oxygen-carrying ferrous $\left(\mathrm{Fe}^{2+}\right)$ state, [9] provided that G-6PD levels are normal and there is adequate production of NADPH to reduce methylene blue to leukomethylene blue. "Blue cures blue but be cautious." One should be cautious in the administration of methylene blue in G-6PD deficiency patients; the reason being G-6PD deficiency can cause dapsone-induced hemolytic anemia but not methemoglobinemia unless concurrent oxidizing drugs are given [10].

\section{Conclusion}

Adverse effects associated with dapsone therapy should be kept in mind while prescribing it, and if a patient using dapsone develops any adverse signs and symptoms like dyspnea and hypoxemia, they should be suspected of dapsone induced methemoglobinemia. And methylene blue is the antidote against methemoglobinemia, provided that G6PD levels in the body are normal.

\section{Conflict of Interests}

None.

\section{References}

1. Oliveira FR, Pessoa MC, Albuquerque RFV, Schalcher TR, Monteiro MC (2014) Clinical applications and methemoglobinemia induced by dapsone. J Brazil Chem Soc 25(10).

2. Shivinder S, Navdeep S, Sushmitha P, Gouri SR (2014) Dapsoneinduced methemoglobinemia: "Saturation gap"-The key to diagnosis. J Anaesthesiol Clin Pharmacol 30(1): 86-88.

3. Denis PP (2002) methemoglobenemia.In. In: goldfranks's toxicological emergencies. MCgraw hill, New York, USA, pp: 1438-1439.

4. David SR, Sawal NS, Bin Hamzah MN, Rajabalaya R (2018) The blood blues: A review on methemoglobinemia. J Pharmacol Pharmacother 9: $1-5$.

5. Anna S, Dominique LC, Robin K (2011) Methemoglobinemia: Pathogenesis, Diagnosis, and Management, South med J 104(11): 757761.

6. Nabukeera-Barungi N, Mworozi E (2012) Sudden onset methaemoglobinaemia in a previously well Ugandan child: A case report and literature review. Pan Afr Med J 11: 49

7. Stichtenoth D (2012) Lip cyanosis in dapsone therapy: Should the dosage be reduced? MMW Fortschr Med 154: 32.

8. Khanal R, Karmacharya P, Pathak R, Poudel DR, Ghimire S, et al. (2015) Do all patients with acquired methemoglobinemia need treatment? A lesson learnt. J Community Hosp Intern Med Perspect 5: 29079

9. Boylston M, Beer D (2002) Methemoglobinemia: A case study. Crit Care Nurse 22: 50-55.

10. Bhushan M, Piyush K, Poonam K, Adarsh LS (2016) How to manage a side effect: Dapsone-induced methemoglobinemia. Indian journal of drugs in dermatology 2(2): 117-120. 


\section{ISSN: 2574-1241}

DOI: $10.26717 /$ BJSTR.2021.32.005326

Shahzaib Ahmad. Biomed J Sci \& Tech Res

(C) C) This work is licensed under Creative

Submission Link: https://biomedres.us/submit-manuscript.php

$\begin{array}{ll}\text { BIOMEDICAL } & \text { Assets of Publishing with us } \\ \text { RESEARCHES } & \text { Global archiving of articles } \\ \text { - Immediate, unrestricted online access } & \text { - Rigorous Peer Review Process } \\ & \text { - Authors Retain Copyrights }\end{array}$

